Supporting Information

\title{
Kinetic Analysis of Microbial Reduction of Fe(III) in Nontronite
}

\author{
Deb P. Jaisi ${ }^{1}$, Hailiang Dong ${ }^{{ }^{*}}$, and Chongxuan Liu ${ }^{2}$ \\ 1: Department of Geology \\ Miami University \\ Oxford, OH 45056;
}

2: Pacific Northwest National Laboratory

Richland, WA 99352

*Corresponding author:

Hailiang Dong

Department of Geology

Miami University

Oxford, $\mathrm{OH} 45056$

Tel: $513-529-2517$

Fax: 513-529-1542

Email: dongh@muohio.edu 


\section{Figure Captions}

Fig. S1. The remaining free sorption sites of $\mathrm{Fe}(\mathrm{III})$ on NAu-2 and cell surfaces as a function of biogenic Fe(II) produced. Speciation of biogenic Fe(II) onto bacterial and clay surfaces was calculated using Langmuir isotherm constants for cell and nontronite surfaces (Eq. 1). The remaining free sorption sites were calculated from the initial number of sorption sites available on CN32 cells and NAu-2 at time 0 and the number of sorption sites blocked by biogenic Fe(II) at a given time $t$ assuming a stoichiometric ratio of 2.2. The triangles and squares are the free sorption sites remaining on nontronite and $\mathrm{CN} 32$ cells, respectively. The lines are connection to the data points (not fitting lines). The initial number of Fe(III) sorption sites were calculated from sorption isotherms.

Fig S2. Kinetics of Fe(II) sorption onto NAu-2 surfaces. The experiments were performed at a clay concentration of $5 \mathrm{mg} / \mathrm{mL}$. The experimental tubes were continuously shaken at $60 \mathrm{rpm}$ at $30^{\circ} \mathrm{C}$.

Fig S3. Kinetics Fe(II) sorption onto CN32 cell surfaces. Time course sorption experiment of Fe(II) sorption on CN32 cells at $10^{8}$ cells $/ \mathrm{mL}$ with an initial $\mathrm{Fe}(\mathrm{II})$ concentration of $0.5 \mathrm{mM}$.

Fig S4. SEM image showing aggregated NAu-2 particles. This aggregation effect may be facilitated by sorbed Fe(II) and high clay concentration.

Fig S5. Sorption of Fe(II) concentration onto cell -- NAu-2 mixture at an NAu-2 and cell concentration of $5 \mathrm{mg} / \mathrm{mL}$ and $1 \times 10^{8}$ cells $/ \mathrm{mL}$, respectively. These are typical concentrations used in a normal reduction experiment.

Fig S6. Change of CFU counts over the course of the Fe(III) bioreduction (corresponding to Fig. 5).

Fig. S7. SEM image showing a cluster of Shewanella putrefaciens CN32 cells on NAu-2 surfaces. This image suggests that $\mathrm{Fe}(\mathrm{III})$ sites on NAu-2 surfaces may become insufficient for cell attachment 
when cell concentration is increased. 


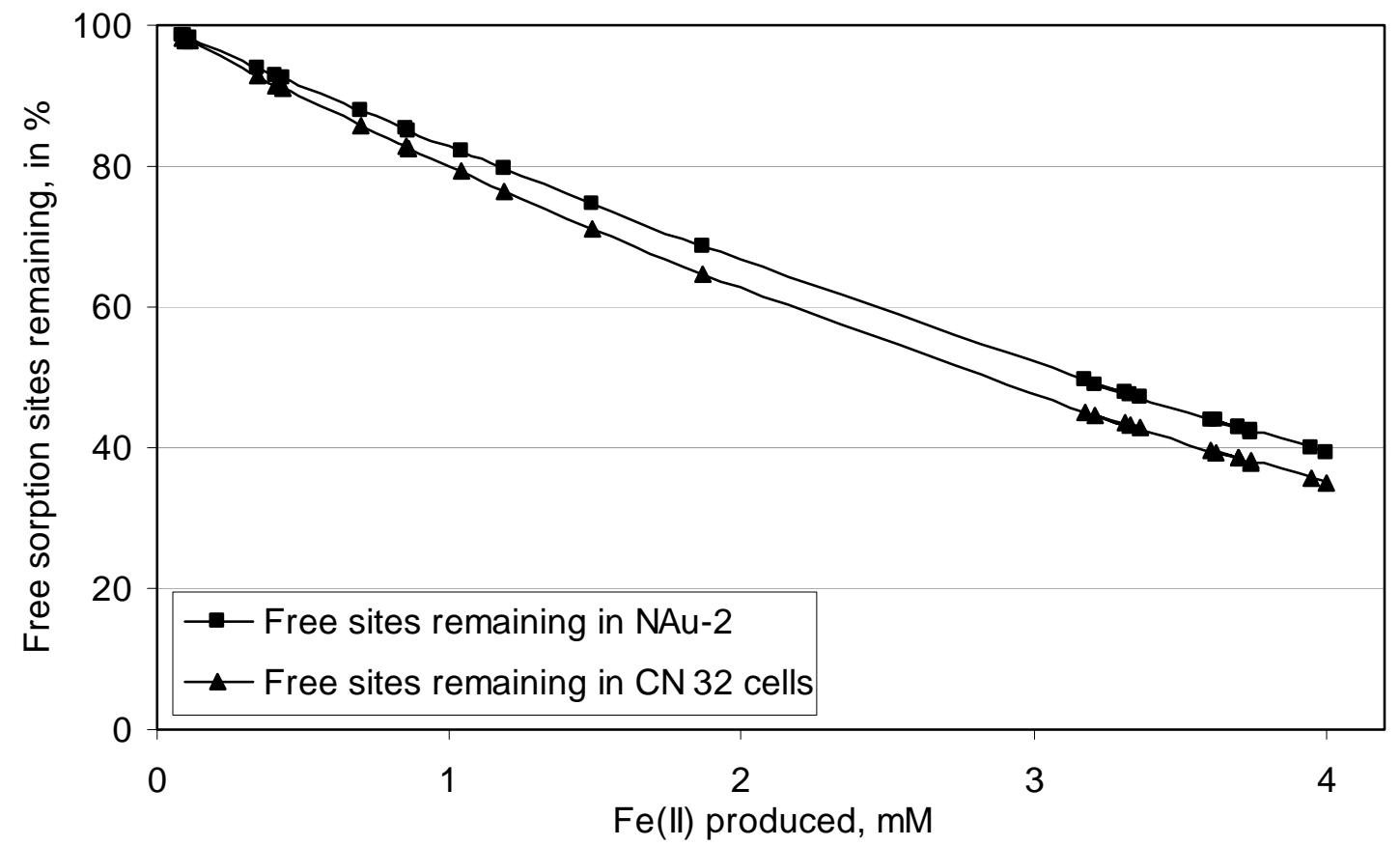

Fig. S1

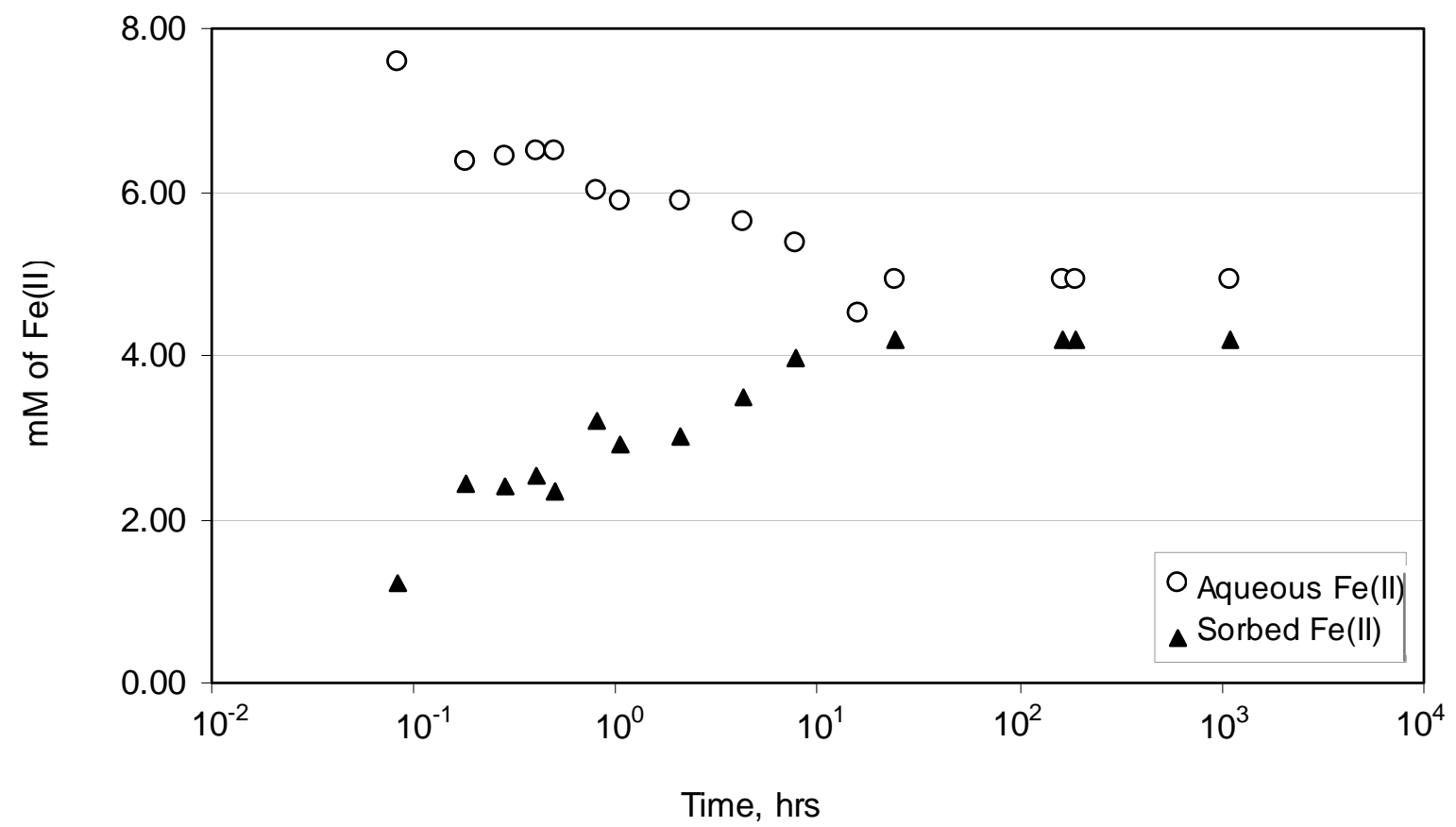

Fig. S2 


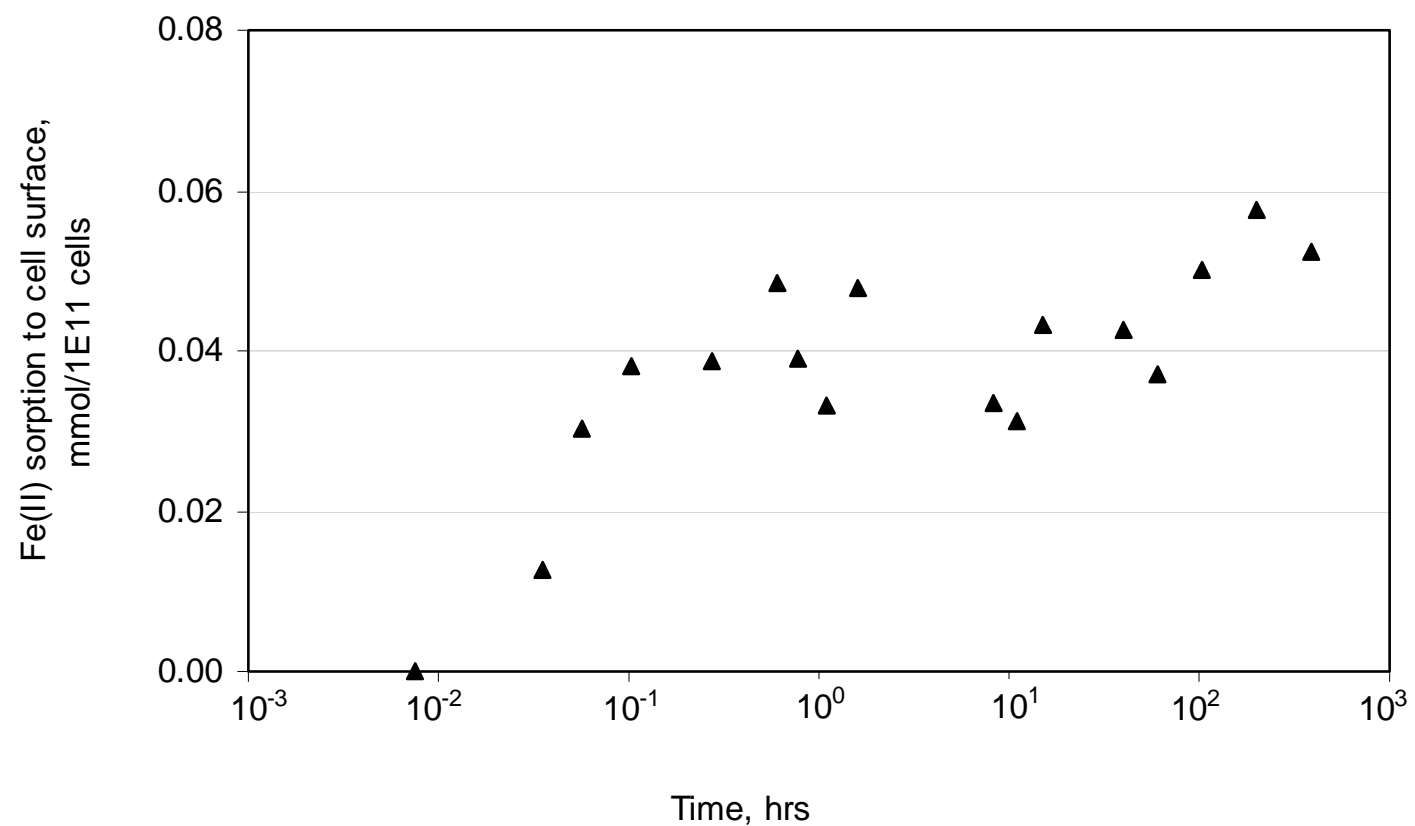

Fig S3

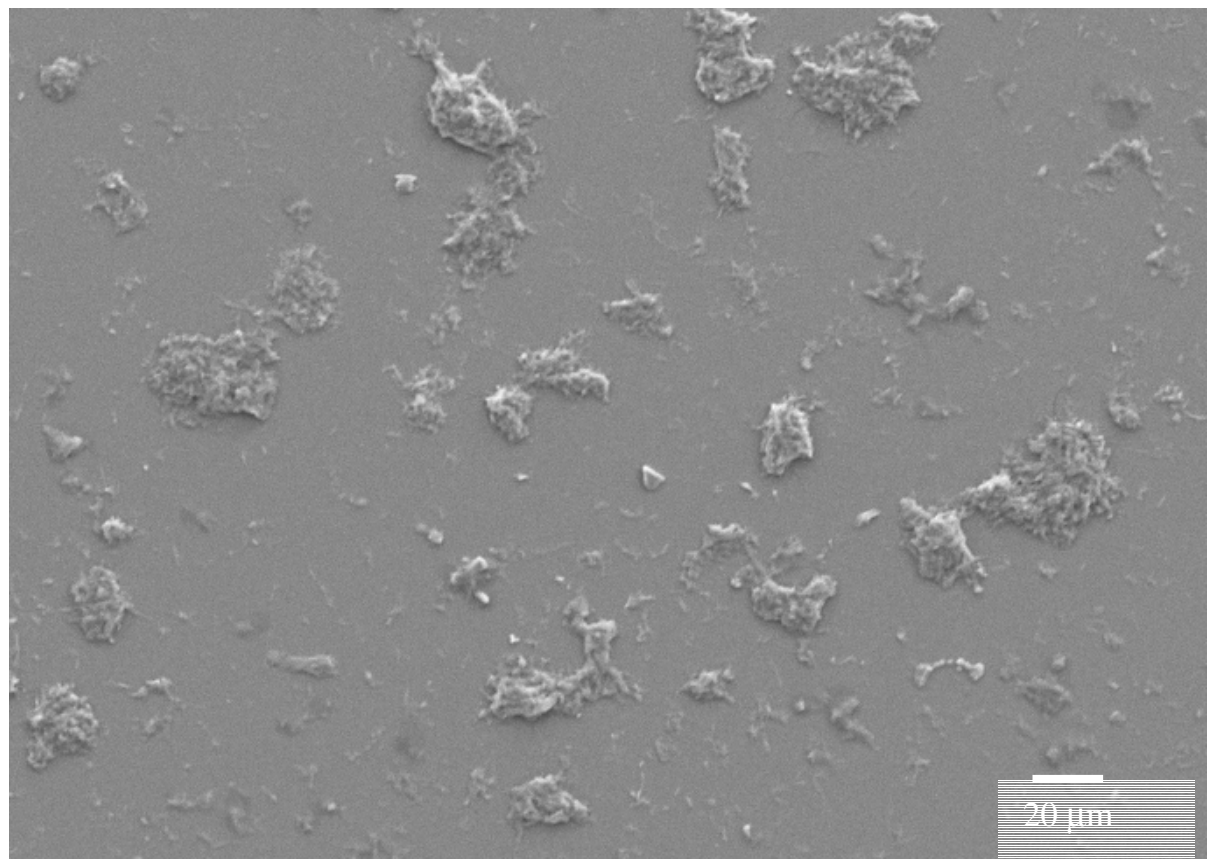

Fig. S4 


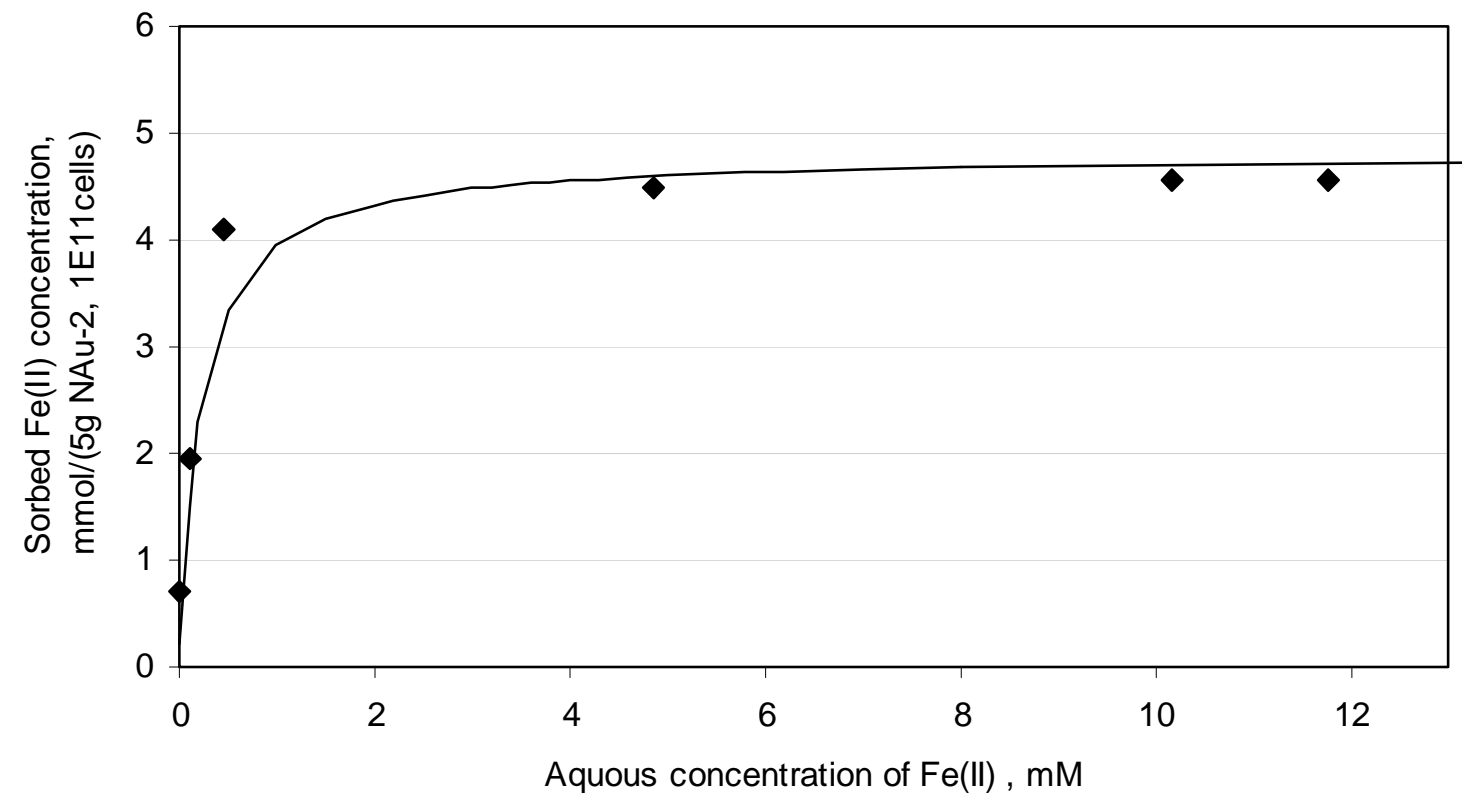

Fig S5

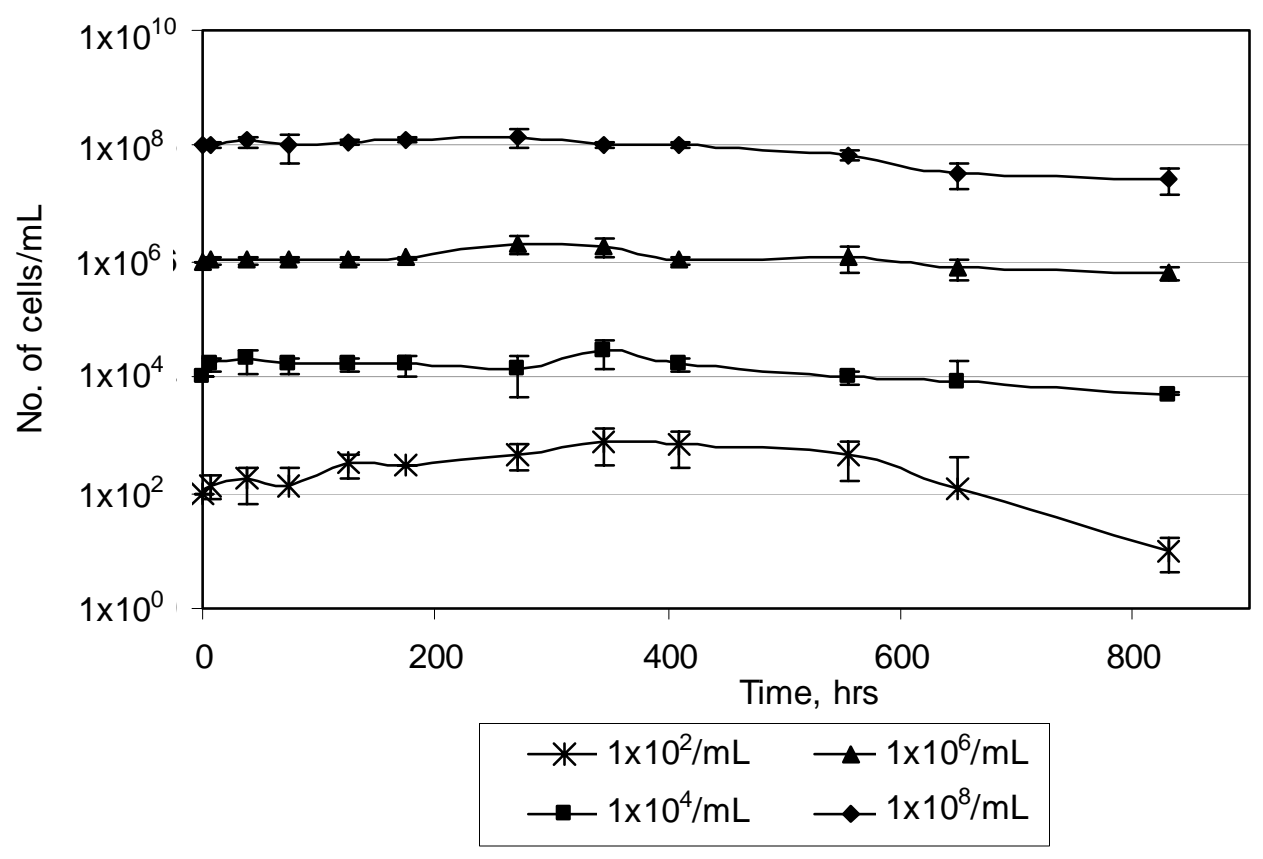

Fig. S6 


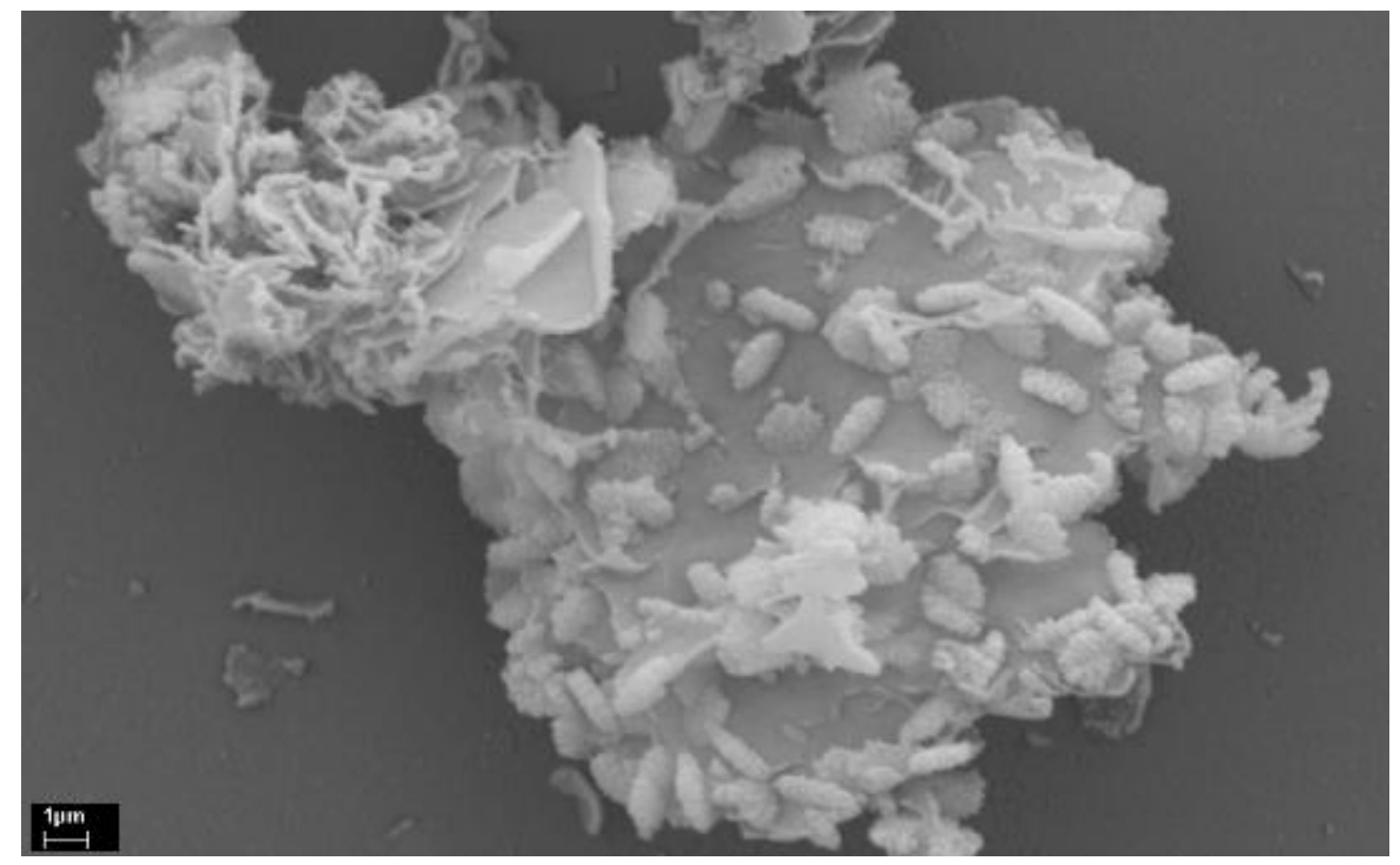

Fig. S7 